\title{
Advancing Safety in Organisations: Application via the Luton Safety Stack
}

\author{
Job Smeltink ${ }^{1, *}$, Sybert Stroeve ${ }^{1}$ and Barry Kirwan ${ }^{2}$ \\ 1 Safety Institute, Netherlands Aerospace Centre NLR, The Netherlands \\ ${ }^{2}$ EEC, Eurocontrol, France
}

\begin{abstract}
Controlling and improving safety in organisations is achieved using a Safety Management System (SMS). Notwithstanding the variety of components considered in SMS standards, including human factors and safety culture, safety management systems are sometimes observed by those at the 'sharp end' as being bureaucratic, distinct from actual operations, and being too focused on the prevention of deviations from procedures, rather than on the effective support of safety in the real operational context. The soft parts of advancing safety in organisations, such as the multitude of interrelations and the informal aspects in an organisation that influence safety, are only considered to a limited extent in traditional safety management systems. The research in Future Sky Safety Project 5 (FSS P5) focused on improving these human-related, informal organisational aspects. Since every organisation is unique, in the operations it conducts, its history, and its organisational culture, there cannot be a one-size-fits-all standard for advancing safety in organisations. Rather, this needs to be based on the organisation at hand, leading to tailored solutions. This has been applied to a safety culture assessment and enhancement approach applied for six key organisations at London Luton Airport, and the approach has become known as the Luton Safety Stack. The six organisations decided to share the detailed results of their individual safety culture assessments. They formed a group that holds quarterly meetings, which always include a workshop element. From this approach, the organisations were stimulated to develop harmonised procedures for all ground-handling operators at Luton, and for each operation, creating a simple one-page procedure with diagrams, to keep it simple and safe. The Luton Safety Stack shows that when organisations share a place, such as at an airport, they need the opportunity to meet to discuss both potential safety threats, and opportunities to advance safety, because even through organisations are interdependent, safety issues in one organisation often have implications for others.
\end{abstract}

Keywords: Safety Management; Safety Culture; Organisational Risk.

\section{INTRODUCTION}

Safety in aviation has improved significantly over time. Developments in technology and airframes, automation, standardisation, safety protocols, regulation, aircrew training, working directives, the external environment, and professional standards have contributed to this. Currently, the safety focus shifts towards the organisational factors. James Reason (1997) popularised the term "organisational accident". Organisations can lay the conditions for errors, behaviour, workarounds, etc. that result in (organisational) accidents, and human error is often seen as a symptom of problems deeper in the organisation. Reason stresses the multi-level contributions: "Organisational accidents arise from the concatenation of several contributing factors originating at many levels of the system" (Reason, 2004, p. ii29). Whereas the recognition of such

\footnotetext{
* Corresponding author: +31(0)88 511 3040; Job.Smeltink@nlr.nl
} 
potentially contributing factors can be a first step in improving the safety performance in an organisation, the way that an organisation can actually adapt so as to achieve an improvement in safety performance does not straightforwardly follow from such factors. Rather it depends on complex combinations of "soft" factors, such as those related to safety culture, as well as on hard factors, such as those related to formally defined activities in an organisation's safety management system.

To address the organisational factors in safety, a range of theoretical approaches have been proposed over the last three decades, from Normal Accidents, Swiss Cheese models and High Reliability Organisation theory, to Safety Culture Measurement, Safety Mindfulness, Resilience Engineering and Safety-II (Perrow, 1984; Reason, 1997; Hollnagel et al., 2006). But how many of these approaches have been integrated into the management of safety? It seems that we continue to write about organisational accidents in an academic way rather than resolving them at the operational level.

Future Sky Safety project P5 "Resolving the organisational accident" (FSS P5) aims to improve the safety of aviation organisations by improving relevant organisational processes and structures, and especially by supporting the ways that people at all levels in an organisation understand, behave and interact in safety-relevant situations. Its research incorporates several streams that address top management, middle management, safety dashboards, safety mindfulness, safety culture, agile response capability, and advanced safety management systems. This paper presents an overview of these research streams and illustrates its application to a case study at Luton Airport.

The project is part of the Future Sky Safety (FSS), programme, an EU-funded transport research programme in the field of European aviation safety, with an estimated initial budget of about $€ 30$ million. The particular project brings together 33 European partners to develop new tools and approaches to aviation safety, initially over a four-year period started in January 2015.

\section{IMPROVING SAFETY IN ORGANISATIONS}

The activities performed by organisations to reduce the likelihood of the occurrence of accidents are typically part of the SMS of the organisation and are often related to the safety culture of an organisation. When organisations try to address the organisational factors, they face several challenges. The effort in maintaining and documenting an SMS can be considerable, as it includes a multitude of components and relates in various ways to the design and conduct of operations in an organisation. Notwithstanding the variety of components considered in SMS standards, including human factors and safety culture, safety management systems are sometimes observed by frontline operators (pilots, air traffic controllers, etc.) as being bureaucratic, distinct from actual operations, and too focused on the prevention of deviations from procedures rather than on the effective support of safety in the real operational context. As Bill Voss, President and CEO of Flight Safety Foundation, stated in Aerosafety World (May 2012, p. 1):

'The ICAO guidance was built around the "four pillars," so now everybody has an SMS with four pillars. And of course, now every regulator has a checklist that counts the pillars. We all have policies, posters, forms, processes and meetings. This is all really very comforting to people who have never grasped the concept of risk management. They are reassured by the fact that all they really have to do is fill out the right form and show up at the weekly meeting. Many well-meaning operators have worked themselves into a position where they are spending lots of time and money, but are not necessarily getting the intended results.'

Hence, there is a tension between potential bureaucracy and the potential complexity of effective means for ensuring safe performance in an organisation. Currently, the implemented SMS is commonly structured around compliance with pre-determined practices and standards, and focus on procedures and paper, while they do not actively encourage innovatively creating future 
best practises (HFG:E, 2017). A second challenge is that it is not known what an "optimal" SMS for an organisation should look like. Another challenge is that there is a lot of supporting material available on the "hard" elements of SMS, such as the development of a safety policy, the assignment of roles and responsibilities, and risk assessment procedures. But there is much less available on "softer" elements of SMS, such as a thorough understanding of the safety culture of an organisation and how this relates to safety, how the top and middle managers affect safety, and how to establish the right flow of safety-related information through the entire organisation. We therefore think that the key for an organisation towards improving its safety lies in advancing such informal, human-related, soft elements.

In FSS P5 these challenges are attacked by addressing key safety components within an organisation in four research directions [Work Packages (WP) 1 through 4] supplemented with an integration work package 5:

- WP1 - Safety wisdom. Researching the contributions to safety in aviation organisations by top and middle management. Additionally, researching how to improve safety wisdom by identifying best practices for the design and use of safety dashboards.

- WP2 - Safety mindfulness. Developing and implementing a model able to improve the organisational mindfulness - i.e. creating a purposeful flow of relevant and useful information that actively supports, from the one side, operational people's capability to remain mindful of safety when carrying out their activities, and from the other side, managers to remain 'in the loop' and collect useful data to ensure continuity of improvement process.

- WP3 - Safety culture. Extending the safety culture analysis and improvement approach developed for Air Traffic Management (ATM) to other sectors in the air transport system.

- WP4 - Agile response. Developing an agile response capability that addresses events triggered by sudden crises that can spread and affect multiple organisations in the aviation system (e.g. volcanic ash).

- WP5 - Safety performance system. This final WP integrates the foregoing four WPs into a Safety Management Systems framework, lending an organisational risk management capability to help reduce the risks.

To understand how the soft elements function in an organisation, an important focus of this project is on how real safety works in practice. Therefore, during the project, there was significant interaction with practitioners through interviews and real-life application cases. One of these application cases is discussed below. The research has focused on three different layers in an organisation: executives (top management), middle management, and operational and technical staff, as illustrated in Figure 1. 


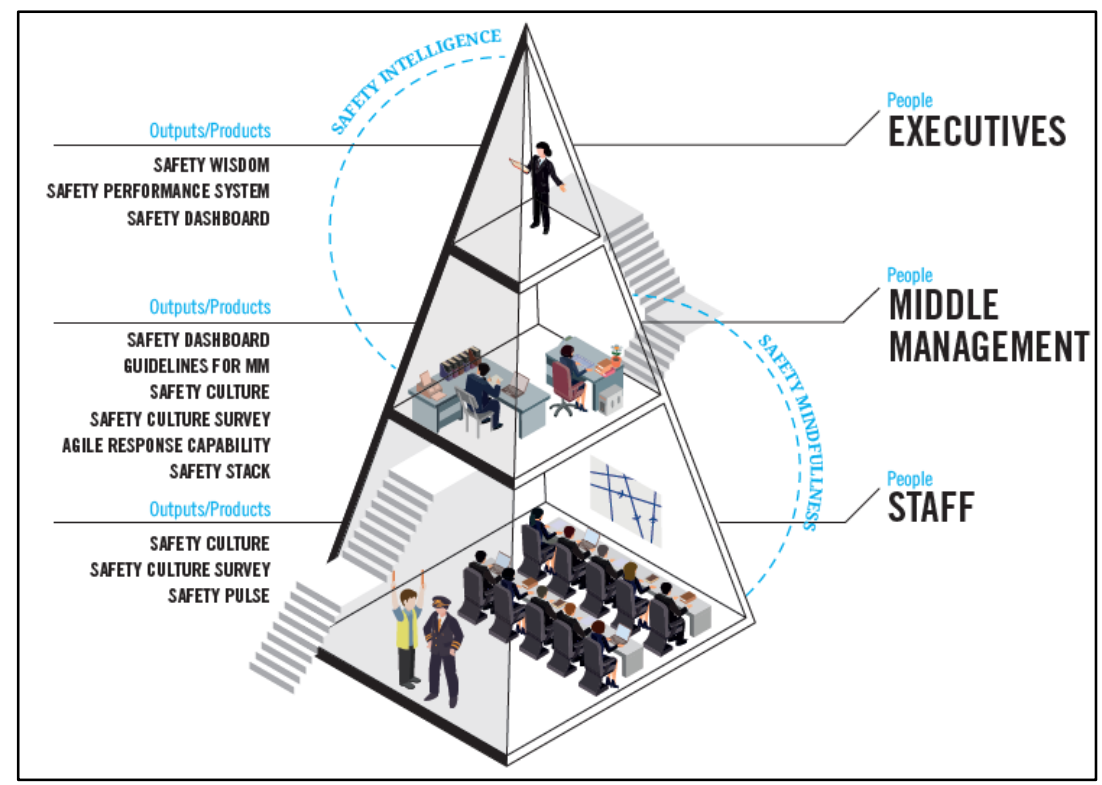

Figure 1: The FSS P5 Pyramid: solving the next organisational accident by offering safety tools to every layer of the organisation. Details on each of the tools are provided on the website http://safeorg.eu

Safety wisdom, as one of the results of the research on top management, provides an analysis of the various views on safety. This supports executives in improving their contributions and leadership regarding safety performance and safety management of their organisations. The middle management research has provided new insights and guidance that organisations can use to harness the role of middle management in safety. The safety dashboard research supports organisations to develop and tune safety dashboards that lay an effective foundation for the information transfer in the organisation's safety management system up to the top executive level to inform decision-making and strategy. The safety mindfulness research has provided new methods and techniques that support the flows of information in an organisation to keep everyone mindful of the potential risks in their role in assuring safety and provide them with the knowledge to do so. The safety culture research has provided a broadened safety culture assessment and enhancement approach which will be described in more detail below. Among others, the safety culture assessment and enhancement approach has been applied to the whole KLM organisation. The agile response capability research has provided new approaches for the development of exercises and preparedness plans for air transport crisis situations, which support organisations to advance their intra- and inter-organisational capability of detecting and flexibly responding to dynamic crisis scenarios. The safety performance system research has provided guidance for the application of the FSS P5 research results to safety management, and it has developed a tool that supports air transport organisations to self-assess their SMS which can be the starting point for improving their SMS.

One of the main conclusions from the FSS P5 research is that every organisation is unique, in the operations it conducts, the education of its personnel, the relationships it has with other organisations, its history, its organisational culture, its relationships with regulators, etc. As a result, every organisation has its own strong and weak elements in assuring the safety of its operations. As such there cannot be a one-size-fits-all approach for advancing safety in organisations. This rather needs to be based on a careful analysis of the organisation at hand, leading to tailored solutions. Therefore, the research has led to a collection of tools which are being showcased on the website SAFEORG.EU ${ }^{\dagger}$ creating an opportunity for proposing their implementation to any interested organisation. The SAFEORG website represents a more user-oriented and user-friendly

\footnotetext{
$\dagger$ The website will be officially launched at the final Future Sky Safety Conference in November 2018, and will be maintained for at least two years after the end of the Future Sky Safety programme.
} 
way of disclosing the FSS P5 products than traditional reports. It will allow interested parties to browse, cherry-pick, and learn of other tools, as they interact with the website, enhancing the overall exploitation of the tools derived from the project.

\section{LUTON SAFETY STACK APPLICATION}

Safety culture has been an important topic in FSS P5 research. Safety culture refers to the norms, values, and practices shared by groups in relation to safety and risk (Guldenmund, 2000). Safety culture research suggests that organisations with a weak safety culture to be more susceptible to accidents (e.g. due to organisations prioritising profit over safety, not learning from incidents), and those with a strong safety culture to be more resilient (e.g. employees can challenge unsafe behaviour, managers ensure resources for safety are available) (Meshkati, 1997). Problems in safety culture within airlines and ATM have consistently been identified as a causal factor in aviation accidents (von Thaden, Wiegmann \& Shappell, 2006; BFU, 2004). To improve and identify problems in safety culture within aviation, researchers have begun systematically measuring safety culture across the industry (Mearns et al., 2013).

In Europe, much of this work has focussed on air traffic management. Over the past 10 years, Eurocontrol and the London School of Economics (LSE) have conducted one of the largest ever investigations of safety culture. By using online questionnaires and follow-up focus groups, safety culture in ATM has been measured in more than 30 countries. This research has resulted in an internationally validated questionnaire tool for measuring safety culture. Within FSS P5 firstly this tool has been made suitable for other aviation sectors, namely airlines, airframe manufacturers and airports. Secondly, the practical connection with safety in operations was made to demonstrate that the safety culture assessment can make a real difference, whether to pilots, controllers, ground handlers, or their managers. Based on the analysed results of the safety culture questionnaire, follow-up workshops were planned to obtain an understanding of the reasons for the safety culture ratings and to identify tailored ways towards improving the safety in an organisation. This approach has been applied at an airport.

At an airport, many organisations must work together to enable smooth and safe airport operations. These organisations range from airlines, air traffic control and ground handlers, to deicers, fuel services, baggage handlers, caterers and cleaning services. They are all interconnected. If one of them has a problem, then this often has an effect on others, also for safety. The need for collaborative safety approaches at an airport has been recognized before, for instance, it was proposed for Amsterdam Airport Schiphol after the crash of a Boeing 747 in 1992 (RAND, 1993).

The initial idea for the Luton Safety Stack came from the ATM safety culture work (Kirwan, Reader \& Parand, 2019). It was noticed regularly that an Air Navigation Service Provider (ANSP) would often mention certain risks or factors as being important for their safety, but over which they had limited control. Their risk management depended on the practices of others, like the airport, ground handlers, airlines, or military operations. These shared risks were effectively safety 'blind spots' since it appeared to the extent that the other organisations were not necessarily aware of the risk they were creating to the ANSP.

Six organisations based at London Luton Airport underwent a safety culture survey. This was the first time this had been done. They then met and compared their results at a high level. Each organisation had a detailed snapshot of its safety culture and its strengths and opportunities for improvement. The six organisations decided to share information on each other's surveys. Not only the high-level results, but especially concerning the areas where they were doing well, and where they needed support. Following these initial results, they formed a group of (currently) 15 organisations, all based at the airport, called the Luton Safety Stack, led by London Luton Airport and assisted by FSS P5. It's called a 'Stack' because the original concept used a vertical representation of the companies, from the ground upwards, and used this word to describe it.

Since January 2017 when it was formed, there have been eight meetings, which always include a workshop element. As an example of Stack activity, in the workshop, the participants are asked to reflect on recent safety incidents that involve more than one stack organisation, e.g. an 
airline, a ground handler, and ATC. They discuss potential solutions to prevent incident recurrence, and then other ground handling companies at the airport agreed to adopt the same solution.

The most tangible outcome so far has been the work on harmonisation of ground handling procedures. At Luton, as at many airports, there are several ground handling organisations and a number of airlines. The way operations are carried out, such as preparing for aircraft arrival, chocking an aircraft, or cone placement around an aircraft can vary between the handlers and the airlines. This variability can lead to inconsistencies, which could allow hazards to appear, or lead to delays. The Luton Safety Stack members are developing harmonised procedures for all operators at Luton, and for each operation, creating a simple one-page procedure with diagrams, to keep it simple and safe. So far, 21 such procedures have been implemented, with another dozen in the pipeline. This initiative has led to several other initiatives like the development of a common safety dashboard for Luton and 'walk in my shoes' opportunities, where people from different jobs can see what it's like to be a controller, a ground handler, a de-icer, etc. to better understand each other at the operational sharp end.

\section{DISCUSSION}

To advance safety in organisations, in addition to the formal elements in SMS, the key lies in advancing informal, human-related, soft elements. It requires a thorough understanding of how the organisation works and how this relates to safety, such as understanding of the safety culture of an organisation, how the top and middle managers affect safety, and how to establish the right flow of safety-related information through the entire organisation. The research performed by FSS P5 has been focused not only on the alignment of processes but also on safety views and values, as well as attitudes and expectations throughout an organisation.

Safety culture and safety management are closely related. The entirety of norms, values and practices with respect to safety and risk in an organisation forms an important foundation for the effectiveness of its safety management and the level of safety that can be achieved in its operational conduct. Therefore, an organisation's safety culture is at the core of human contributions to safety in any air transport organisation. If the level of safety culture is low, it is harder to achieve safety management objectives and to assure the level of safety in the operations. SMS component 4 of ICAO Annex 19 (ICAO, 2016) explicitly describes training, education and communication as part of safety management to achieve a positive safety culture with proper knowledge and awareness of all people in the organization. A key aspect is a safety culture measurement and improvement programme, where safety culture is assessed, weaknesses are identified, and there is continuous planning of safety culture improvements. This considers all safety culture dimensions, including the promotion of a just and open culture for reporting and investigation of occurrences, which is an important basis for effective safety management. The stack approach adds relationships regarding the interactions with external parties. These concern the evaluation and support of the SMS of sub-contractors, the improvement of safety-related interfaces with external parties (e.g. identification of newly developing risks), active sharing of safety data and information with other industry stakeholders, and sharing and learning best practices on operational safety and SMS with industry stakeholders.

From an organisational and operational perspective, every organisation is different. As a result, every organisation has its own strong and weak elements in assuring the safety of its operations. As such there cannot be a one-size-fits-all approach for advancing safety in organisations. Rather this needs to be based on a careful analysis of the problem at hand and the context, leading to tailored solutions. Therefore, a workshop format where the people involved in the operation at the sharp end going into the details is found to be a good setting for creating solutions that work. By looking at weak elements and learning from practices from workshop participants and others, improvements can be developed.

As an example, this has been evidenced at Luton Airport in the area of ground handling, where the local air traffic organisation asked one ground handler to consider altering a procedure, with which they agreed. The other two ground handlers in the meeting immediately agreed to do 
the same, so it is now standardised across all ground handling operations at Luton. Following this kind of interaction, the London Luton Airport (LLA) authority is finding that whereas before one ground handler would call the authority to ask another ground handler to make a change, now they are all talking to each other directly, which is far more efficient while keeping LLA in the loop.

One of the ways in which the Safety Stack approach is different and appears to be having a positive impact is the level of people attending the Stack meetings. These are all people who have their finger on the pulse of operations; in other words, they are not too high up in the hierarchy. This acts as an enabler for the smaller companies who attend, who in other types of meetings often feel that 'their voice is too small' to be heard so that they self-censor themselves. In the Stack meetings, they are not afraid to speak up and voice their opinions, concerns and solution ideas.

The output from the FSS P5 project is a collection of tools that can address various problems in an organisation. Whether or not they can be applied depends on the problem at hand. Two of these tools involve an assessment: the safety culture assessment and the SMS maturity assessment. In FSS P5 these assessment tools have been generalised so that they can be used by all stakeholders in aviation. To use these tools successfully, it is important that they are grounded in practical improvements by linking it to safety at work. Despite existing criticism on these questionnaires (Guldenmund, 2007), these assessments help to identify strong and weak points and are a good starting point for the discussions in a workshop setting.

Another area for safety improvement across organisations is looking at the interfaces. Aviation involves complex interactions between many actors (technical systems and humans) operated by a wide range of stakeholders (e.g., airline operators, aerodrome operators, air navigation service providers) which makes it highly distributed. The way the regulations and SMSs are framed at the moment, it is as if to say that if each organisation manages its own safety, then all will be well. This is a limited vision as it neglects the interfaces between organisations. So, the way forward is an inter-organisational collaboration for safety coming from the industry.

The Luton Safety Stack shows that when organisations share a place, such as at an airport, they must have the opportunity to meet to discuss problems and opportunities because the organisations are interdependent and safety issues in one organisation can have implications for others. The Luton Safety Stack provides an example of a collaborative initiative to help manage safety across interfaces, based on sharing good practices and working on safety practice development.

An important ingredient is that the participants at the workshops should have sufficient influence within their organisations so that changes are actually being made. This issue was also raised by the Dutch Safety Board (2017). This ingredient appears to be there in the Luton Safety Stack. At the most recent meeting, Stack organisations were asked why they found the Luton Safety Stack useful. The top replies included "We are experiencing safety as a culture, not as a process or paperwork'; "We see that change is possible"; "We all share the same values, and have common safety concerns"; "Trust is building up after each stack meeting as this is a very open forum"; and "We are busting preconceptions about other people's jobs." The Luton Safety Stack is clearly not a 'paper-based, bureaucratic system'. It remains to be seen if the stack idea will be adopted at other locations.

\section{CONCLUSIONS}

Future Sky Safety project P5 "Resolving the organisational accident" (FSS P5) aims to improve the safety of aviation organisations by improving relevant organisational processes and structures, and especially by supporting the ways that people at all levels in the organisation understand, behave and interact in safety-relevant situations. The project has been focussing on the soft elements of an SMS including the safety culture. An important element in the project was on how real safety works in practice. Therefore, there was significant interaction with practitioners through interviews and real-life application cases. From this project, a number of lessons can be learnt for improving the safety in organisations. 
Realising that every organisation is different, no one-size-fits-all solution can be found, but the improvement of safety in organisations focuses on the specific problem at hand and its context. Improvements following the project were obtained by not only aligning processes but also by aligning information and safety views. The output from the FSS P5 project is a collection of solutions that address various problems in an organisation to showcase the possible implementations. Two of these tools involve an assessment: the safety culture assessment and the SMS maturity assessment. To use these tools successfully, it is important that they are grounded in practical improvements by linking it to safety at work. This is achieved through workshops. The assessments are a good starting point for the discussions in such a workshop setting.

Since aviation involves complex interactions between many actors operated by a wide range of organisation, the interfaces between organisations are important. Currently, the regulations and SMSs mainly focus on individual organisations. This is a limited vision as it neglects the interfaces between organisations. The Luton Safety Stack provides an example of a collaborative initiative to help manage safety across interfaces, based on sharing good practices and collaborating on safety practice development. Such sharing and collaboration benefit the individual organisations and support airport safety as a whole, making it more resilient against existing and developing safety threats.

\section{ACKNOWLEDGEMENTS}

This publication is based on work performed in Future Sky Safety, which has received funding from the European Union's Horizon 2020 research and innovation program under grant agreement No 640597. Any dissemination reflects the authors' view only, and the European Commission is not responsible for any use that may be made of the information it contains.

The authors would like to thank all the researchers and organisations participating in the project Future Sky Safety P5 "Resolving the organisational accident": Eurocontrol, Airbus, Boeing, Deep Blue, ENAV (the Italian ANSP), KLM, London School of Economics, Trinity College Dublin and the Netherlands Aerospace Centre NLR.

\section{REFERENCES}

Bundesstelle für Flugunfalluntersuchung [BFU] (2004). Investigation Report, Accident 1 July 2002 (near) Ueberlingen/Lake of Constance/Germany. Report number AX001-1-2/02, May 2004. Retrieved from: https://www.bfu-web.de/EN/Publications/Investigation\%20Report/2002/ Report_02_AX001-1-2_Ueberlingen_Report.pdf?_blob=publicationFile

Dutch Safety Board (2017). Summary Schiphol air traffic safety. The Hague. Retrieved from: https://www.onderzoeksraad.nl/nl/page/4247/investigation-into-air-traffic-safety-atamsterdam-airport-schiphol.

Guldenmund, F.W. (2000). The nature of safety culture: a review of theory and research. Safety Science 34(1-3): 215-257.

Guldenmund, F.W. (2007). The use of questionnaires in safety culture research - an evaluation. Safety Science 45(6): 723-743.

Hollnagel, E., Woods, D.D., Leveson, N. (2006. Resilience engineering: Concepts and precepts. Ashgate, Aldershot, England.

Human Factors Group: Engineering (HFG:E) (2017). Achieving peak safety performance: listening and learning. In Aerospace March 2017, pp 26-29.

ICAO (2016). Annex 19 - Safety management. Second edition ed: International Civil Aviation Organization. ISBN 978-92-9249-965-5.

Kirwan, B., Reader, T. and Parand, A. (2019: in press) The Safety Culture Stack - the next evolution of safety culture? Safety \& Reliability.

Mearns, K., Kirwan, B., Reader, T.W., Jackson, J., Kennedy, R., and Gordon, R. (2013). Development of a methodology for understanding and enhancing safety culture in Air Traffic Management. Safety Science 53:123-133. doi: 10.1016/j.ssci.2012.09.001. 
Meshkati, N. (1997). Human performance, organizational factors and safety culture. Paper presented at the National Transportation Safety Board symposium on corporate culture in transportation safety. Arlington, VA, April 1997.

Perrow, C. (1984). Normal accidents: Living with high-risk technologies. Basic Books, New York.

RAND (1993). Airport Growth and Safety: A Study of the External Risks of Schiphol Airport and Possible Safety-Enhancement Measures. RAND report, ISBN: 0-8330-1418-8, Santa Monica, CA: Rand.

Reason, J. (1997). Managing the risk of organizational accidents. Aldershot, England Ashgate.

Reason, J. (2004). Beyond the organizational accident: the need for "error wisdom" on the frontline. Quality and Safety in Health Care. 13(Suppl II), ii28-ii33. Retrieved from http://qualitysafety.bmj.com/content/13/suppl_2/ii28.full.pdf+html.

von Thaden, T.,Wiegmann, D., \& Shappell, S. (2006). Organizational factors in commercial aviation accidents. The international journal of aviation psychology. 16(3), 239-261.

Voss, B. (2012). SMS Reconsidered, Aerosafety World (May 2012). 